\title{
Geophysical evaluation of groundwater potential in part of southwestern Basement Complex terrain of Nigeria
}

\author{
Olateju O. Bayewu ${ }^{1}$ (D) Moroof O. Oloruntola ${ }^{2} \cdot$ Ganiyu O. Mosuro ${ }^{1} \cdot$ \\ Temitope A. Laniyan ${ }^{1} \cdot$ Stephen O. Ariyo $^{1} \cdot$ Julius O. Fatoba $^{3}$
}

Received: 22 April 2017/ Accepted: 12 September 2017/Published online: 18 September 2017

(c) The Author(s) 2017. This article is an open access publication

\begin{abstract}
The geophysical assessment of groundwater in Awa-Ilaporu, near Ago Iwoye southwestern Nigeria was carried out with the aim of delineating probable areas of high groundwater potential. The area falls within the Crystalline Basement Complex of southwestern Nigeria which is predominantly underlain by banded gneiss, granite gneiss and pegmatite. The geophysical investigation involves the very low frequency electromagnetic (VLF-EM) and Vertical Electrical Sounding (VES) methods. The VLF-EM survey was at $10 \mathrm{~m}$ interval along eight traverses ranging between 290 and $700 \mathrm{~m}$ in length using ABEM WADI VLF-EM unit. The VLF-EM survey was used to delineate areas with conductive/fractured zones. Twenty-three VES surveys were carried out with the use of Campus Ohmega resistivity meter at different location and at locations areas delineated as high conductive areas by VLF-EM survey. The result of VLF-EM survey along its traverse was used in delineating high conductive/fractured zones, it is, however, in agreement with the delineation of the VES survey. The VES results showed 3-4 geoelectric layers inferred as sandy topsoil, sandy clay, clayey and fractured/fresh basement. The combination of these two methods, therefore, helped in resolving the prospecting location for the groundwater yield in the study area.
\end{abstract}

Olateju O. Bayewu

tejubpositive@yahoo.com

1 Department of Earth Sciences, Olabisi Onabanjo University, Ago Iwoye, Nigeria

2 Department of Geosciences, University of Lagos, Lagos, Nigeria

3 Department of Applied Geophysics, Federal University Oye, Oye Ekiti, Nigeria
Keywords Groundwater potential · Resistivity survey · VES · VLF-EM · Fracture - Geoelectric layer

\section{Introduction}

In hard rock terrains, groundwater potential mapping is relatively complex due largely to highly variable nature of the geological terrain (Kellgren 2002: Anbazhagan et al. 2011) extensive hydrogeological investigations are required in basement complex environment to understand groundwater conditions (Solomon and Quiel 2006; Balamurugan et al. 2008; Pradhan 2009). Evans and Myers 1990; Sener et al. 2005; Singh and Singh 2009; Sharma and Kujur 2012 all noted that several methods commonly adopted in delineating groundwater potential depending on the available data which include remote sensing and Geological Information System(GIS). Several statistical methods can also be adopted for groundwater mapping where adequate information on different influencing parameters to groundwater accumulation and movement are available. These include frequency ratio (Davoodi et al. 2013), multi-criteria decision evaluation (Murthy and Mamo 2009; Kumar et al. 2014), logistic regression model (Ozdemir 2011), weights-of-evidence model (Ozdemir 2011; Pourtaghi and Pourghasemi 2014), random forest model (Rahmati et al. 2016 Naghibi et al. 2016), maximum entropy model (Rahmati et al. 2016), boosted regression tree (Naghibi et al. 2016; Naghibi and Pourghasemi 2015), classification and regression tree (Naghibi et al. 2016), multivariate adaptive regression spline model (Zabihi et al. 2016), certainty factor model (Zabihi et al. 2016), evidential belief function (Pourghasemi and Beheshtirad 2015; Naghibi and Pourghasemi 2015), and generalized linear model (Naghibi and Pourghasemi 2015). These information are lacking in many third world country 


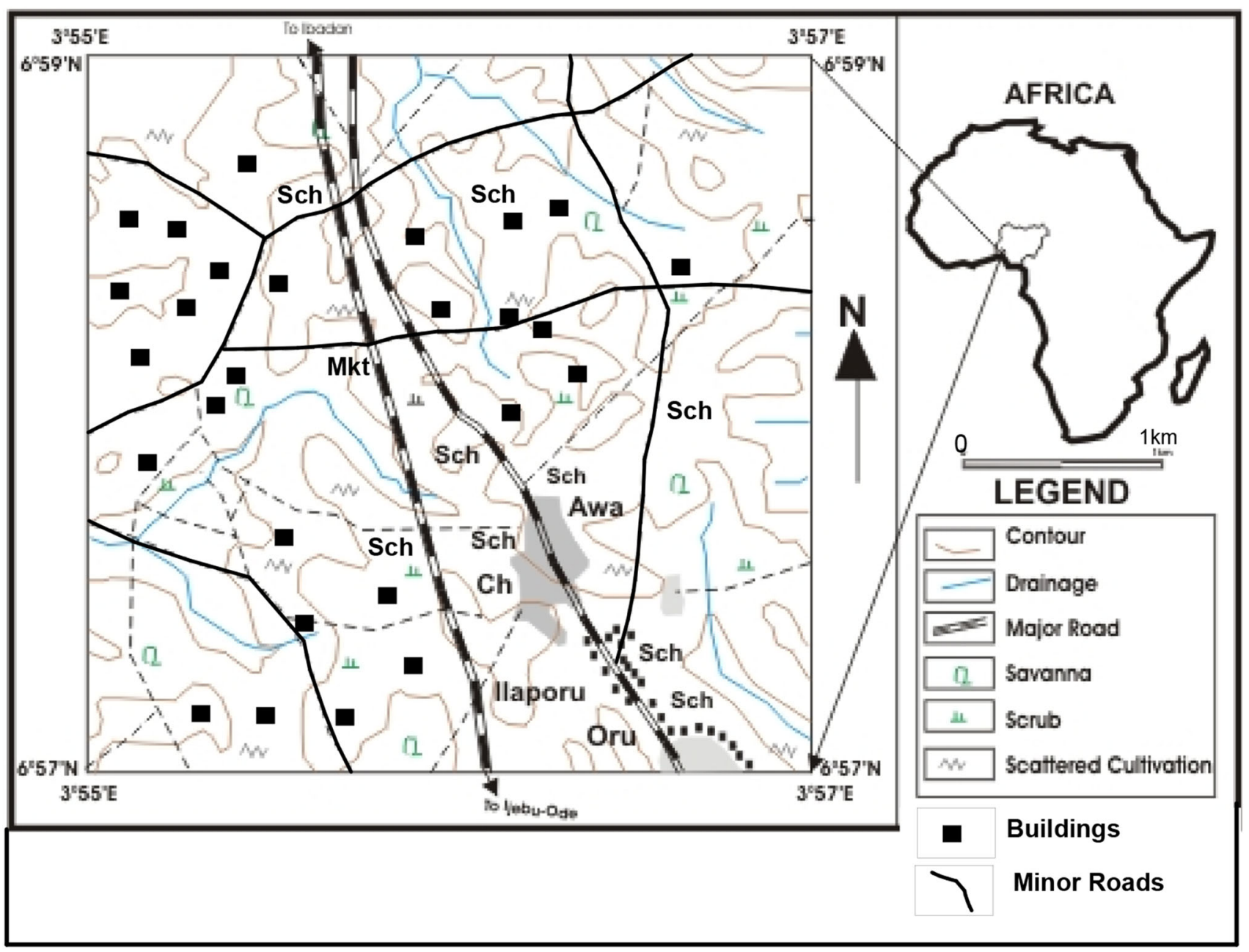

Fig. 1 The location map of the study area

hence proper understanding of hydrogeological characteristics for successful exploitation of groundwater in basement areas depend largely on geophysical methods.

Various forms of water exploratory projects are used in the provision of potable water for human usage and great importance is geophysics which serves as important tool in exploration. Offodile (1983) documented that careful studies accompanied by improved drilling techniques yield favorable results even in problematic areas. Geophysical methods, therefore, play an important role in the exploration of suitable and productive groundwater reservoirs. The geophysical survey is employed to determine geoelectric parameters of formations, identify aquifer units and also determine its depth and lateral extent (Telford et al. 1976).

The types of geophysical method used for a survey depends mainly on the extent or size of area to be surveyed, the cost of the survey, geology of the area and the ease of the interpretation of data obtained. It also provides information on the depth of water table, the lithology in the subsurface layering and ensures a higher degree of accuracy in the location of hydro resources (Omosuyi et al. 2003). They are important in the search and location of suitable groundwater potentials either singly or combined. Various combinations of geophysical methods have been used with an accompanying increase in the degree of accuracy in the location of suitable groundwater reservoir. A combination of the electromagnetic method and the electrical resistivity gave a higher rate of $90 \%$ as opposed to $82 \%$ by the electromagnetic method and the $85 \%$ by the resistivity method (White 1986).

In areas underlain by crystalline rocks, groundwater occurs in fracture zone or in highly weathered basement (Olorunfemi and Fasuyi 1993; Ariyo et al. 2003). The electromagnetic and resistivity methods are both responsive to water bearing basement fracture columns due to the relatively high bulk electric conductivities, both methods were, therefore, found relevant and were hence integrated in the geophysical investigation. The VLF-EM method was adopted as a fast reconnaissance tool to map possible linear 
Fig. 2 Map of the study area showing the location of the VES points and VLF Traverse in the study area
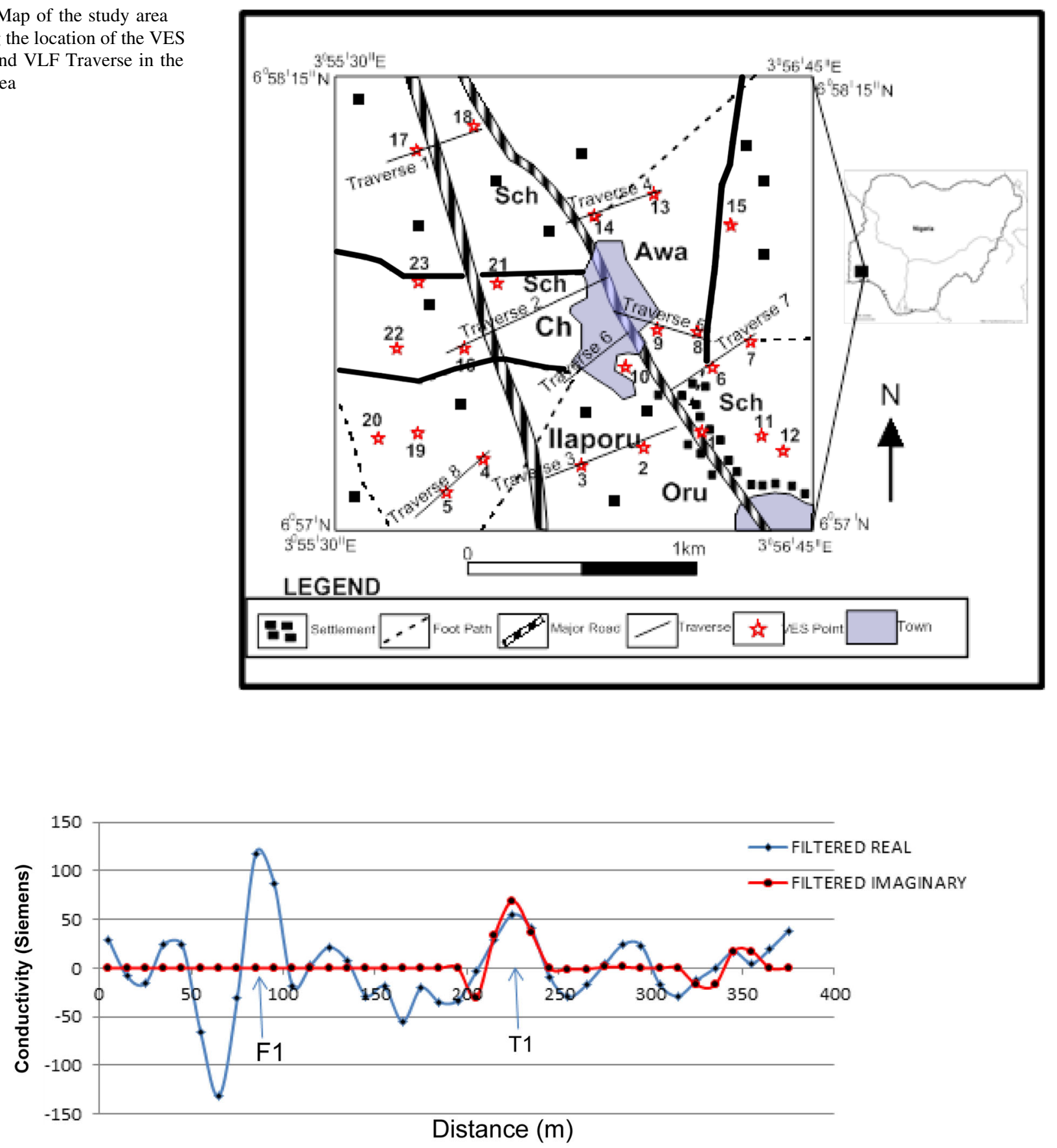

Teros-H jelt filtering

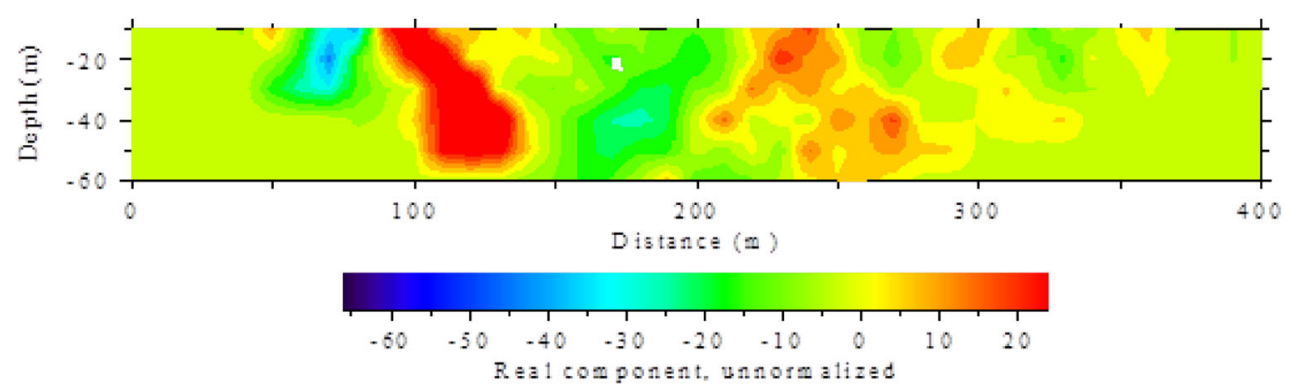

Fig. 3 The VLF-EM traverse and Karous-Hjelt pseudosection for Traverse 1 

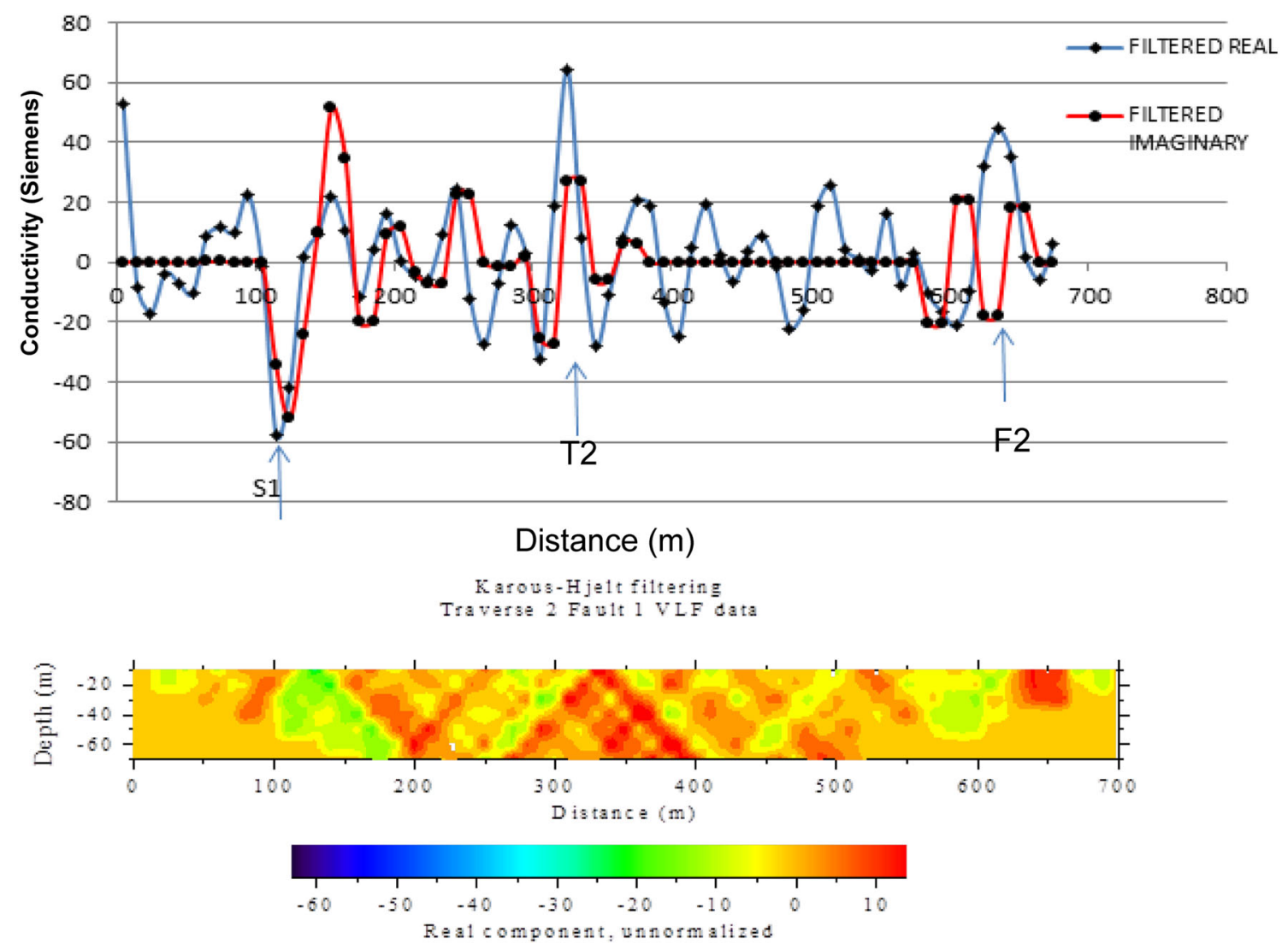

Fig. 4 The VLF-EM traverse and Karous-Hjelt pseudosection for Traverse 2

features such as; fault, and fracture zones while the electrical resistivity method was used to investigate prominent electromagnetic anomalies and provide a geo-electric image or section of the subsurface sequence.

In spite the many studies (Olorunfemi and Olorunniwo 1985; Olayinka and Olorunfemi 1992; Okwueze 1996; Oladapo and Akintorinwa 2007; Oloruntola and Adeyemi 2014) on groundwater potential in many parts of Nigeria, most of the studies were carried out in urban centers such as Lagos, Abeokuta, Ibadan where hydrogeological information is readily available. Awa-Ilaporu, SW is located within the Basement Complex terrain of southwestern Nigeria like many areas in southwestern Nigeria it is a community of indigenous rural people and students of a non-residential Olabisi Onabanjo University, which lacks municipal water supply. The inhabitants rely mainly on low yield, pollution prone shallow wells many of which dries up during dry season. Most of the attempts to construct deeper borehole have either failed outrightly or produced low yield borehole. As a result of this, the need to explore other promising high water yield areas to supplement water supply mostly during the dry season or drought is obvious, hence the need for a more detailed evaluation of the groundwater potential of the community.
The aim of this study is, therefore, to delineate the groundwater potentials in Awa-Ilaporu, near Ago Iwoye southwestern Nigeria, by determining the depth of occurrence of suitable aquifers; and also to provide background information for the future development of groundwater within the area by delineating potential areas for borehole drilling.

\section{Location of the study area and geological setting}

The study area (Fig. 1) is located in Awa-Ilaporu, near Ago Iwoye, south western Nigeria; it falls between latitude $6^{\circ} 57^{\prime}$ to $6^{\circ} 59^{\prime}$ North of the Equator and longitudes $3^{\circ} 55^{\prime}$ and $3^{\circ} 57^{\prime}$ East of the Greenwich Meridian. The drainage shows a dendritic drainage pattern and the major river in the area is River Ome and all other tributaries take their source from this river. It is located within the tropical rain forest which is characterized by a tropical climate with alternating wet and dry season, within the year. According to Onakomaiya et al. (1992), the wet season spans from March to October and peaks in June/July while the dry season spans from November to February. The mean annual rainfall ranges from 100 to $1500 \mathrm{~mm}$ with average rainfall of about $100 \mathrm{~mm}$. Ogunrayi et al. (2016) observed fluctuations in rainfall and temperature pattern of Akure 


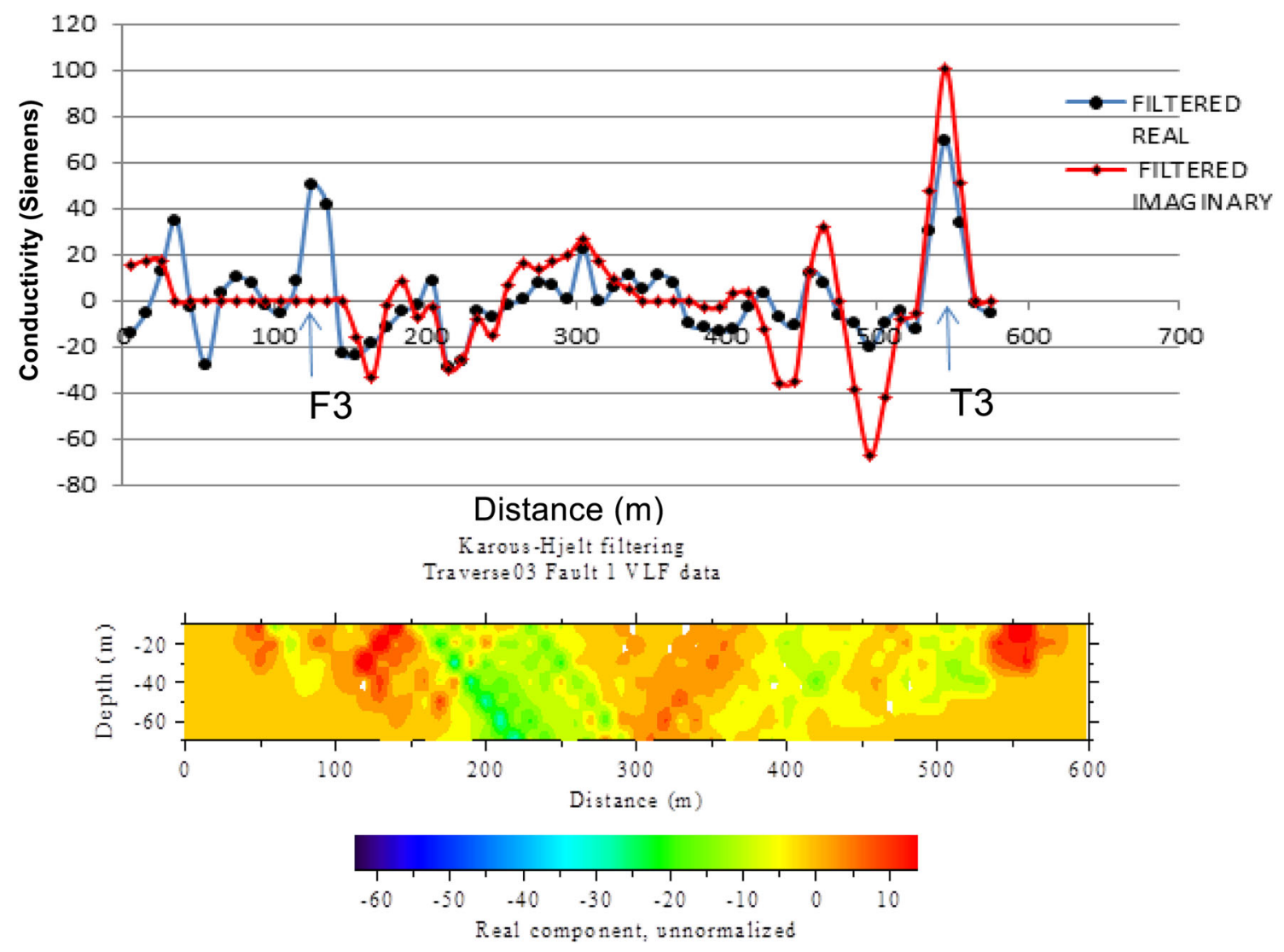

Fig. 5 The VLF-EM traverse and Karous-Hjelt pseudosection for Traverse 3

which is part of southwestern Nigeria, the climate of the region indicates that the beginning of rainfall is becoming earlier which implies possible longer rainy season in the area. The temperature on the other hand, showed an increasing trend indicating warming throughout the year.

There are lots of vegetation covers such as trees, shrubs and grasses. The temperature of the area ranges from 18 to $34{ }^{\circ} \mathrm{C}$ (Iloeje 1986).

The area is found within the southwestern crystalline Basement Complex of Nigeria. Geologically, it is made up of three major rock types; granite gneiss, banded gneiss and pegmatites which serves as an intrusive body. Awa-Ilaporu and environs were in the past agrarian communities with very low population. However, the establishment of the then Off-Campus Ogun State University (now Olabisi Onabanjo University) led to rapid geometric increase in the population of the communities.

\section{Materials and methods}

Two geophysical methods were used for this work; the very low frequency electromagnetic (VLF-EM) and vertical electrical sounding (VES). The location and arrangement of the two methods in the area is shown in Fig. 2.

\section{The VLF-EM survey}

The VLF-EM is a type of continuous wave field electromagnetic method and it is most widely used in the reconnaissance mode. VLF traverses can be run quickly and inexpensively to anomalous areas which may require further investigation either with more detailed geophysical measurement and/or drilling and sampling (Telford et al. 1976). This was one of the methods employed in this research work.

The VLF-EM survey was carried out at different stations and were surveyed at $10 \mathrm{~m}$ interval along eight traverses approximately east-west direction ranging from 290 to 700 metres in length using ABEM WADI VLF-EM unit. The VLF-EM was used to initially delineate areas with conductive or fractured zone.

VLF systems make use of the energy emanating from distant powerful radio transmitters and measure the perturbations in plane-wave radio signal $(15-30 \mathrm{kHz})$. These low frequency signals are trapped between the earth and the ionosphere.

The primary field (the transmitted radio signal) causes eddy currents to be induced in conductive geological units or structure. Faraday's principle of EM induction shows that any oscillating magnetic field (e.g. the radio wave) will 

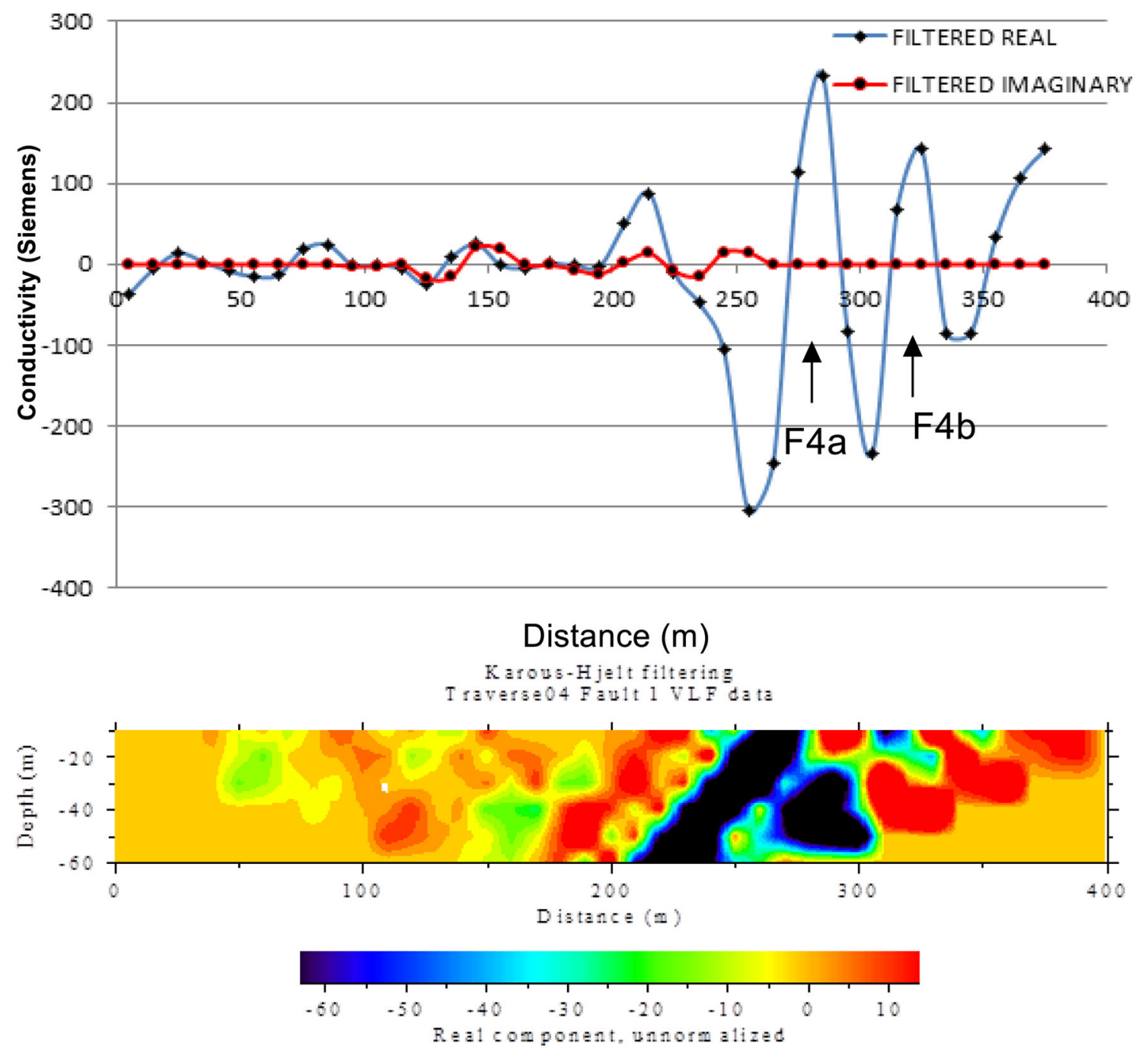

Fig. 6 The VLF-EM traverse and Karous-Hjelt pseudosection for Traverse 4

produce an electric field and electric current in a conductive media. Those eddy currents in turn create a secondary magnetic field which is measured by the VLF receiver. The secondary or perturbed field may be phase shifted and oriented in a different direction than the primary field depending on the shape or geometry of the conductor, the orientation of the conductor and conductivity contrast with the surrounding material (e.g. the host rock). The instrument measures two components of magnetic field or equivalently the "tilt angle" and ellipticity of the field. Some instruments also measure the third magnetic component and/or the electric field. The electrical field is measured by inserting two probes in the ground spaced about 5 meters (McNeil and Labson 1992). VLF interpretation is generally qualitative or subjective in nature and sometimes may be subjected to quantitative interpretation with the aid of filtering technique from which the true filtered real are determined. Anomalous areas are identified and a gross characterization attached to the anomaly (e.g. steeply dipping conductor or thickening conductive overburden). Some simple modeling may be carried out for simple geometric structures (McNeil and Labson 1992).

Data filtering are applied in other to eliminate errors and enhance interpretation of data. This is done by applying a filter operator $(\mathrm{Q})$ which transform true anomaly inflection to peak positive anomalies also referred to as conductivity because they are proportional (Parasnis 1986). The filter operation is given by Fraser (1969):

$\mathrm{F} 1=\left[\left(\Phi_{3}+\Phi_{4}\right)-\left(\Phi_{1}+\Phi_{2}\right)\right] \quad$ Fraser filtering,

where $\Phi_{1}, \Phi_{2}, \Phi_{3}$ and $\Phi_{4}$ are consecutive readings of the measured raw data obtained on the field. 

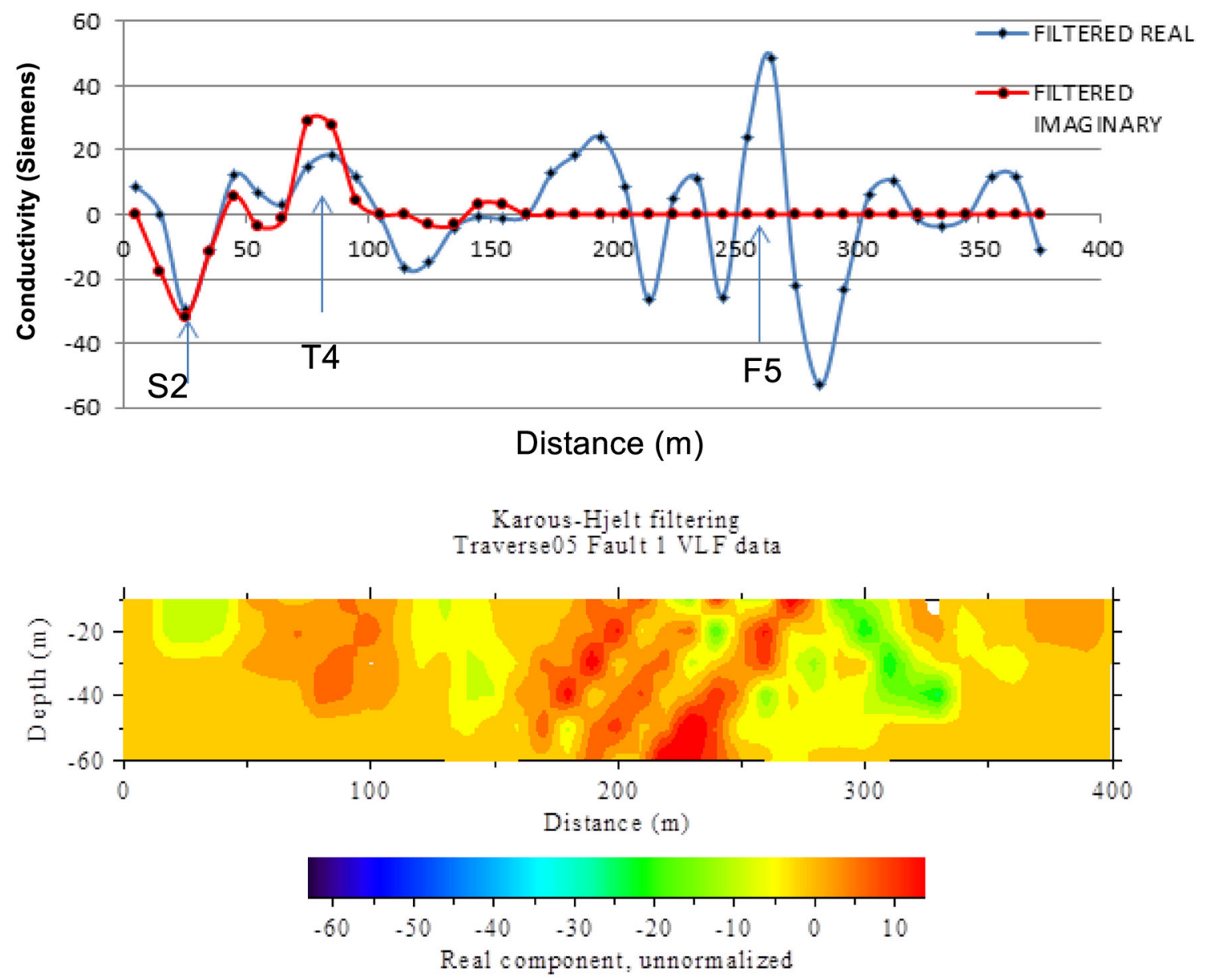

Fig. 7 The VLF-EM traverse and Karous-Hjelt pseudosection for Traverse 5

\section{Vertical electrical sounding (VES) survey}

The second type of geophysical survey method used is the electrical resistivity method using the schlumberger electrode configuration. Twenty-three (23) Vertical Electrical Sounding stations were carried out in the field using OHMEGA resistivity meter which investigates the subsurface resistivity conditions by passing electric current into the ground through a pairs of current electrodes and measuring the resulting voltage differences between pair's potential electrodes. Repeated measurements of current and potential difference were made at these same points using a larger current electrode separation $(\mathrm{AB} / 2)$ in each successive electrode probe to determine the depth to the bed rock. In the probe, the spacing $A B / 2$ was varied in a line direction to a maximum of $100 \mathrm{~m}$ in a station, keeping the center of the electrode configuration fixed. The values obtained were then plotted on a $\log -\log$ paper as points with the resistivity values being on the vertical axis and the current electrode spacing $(\mathrm{AB} / 2)$ on the horizontal axis. The points were joined and curve marched manually using pre-calculated master curves and their auxiliaries. The results obtained from the exercise were used as inputmodel for the eventual computer aided iteration using WINRESIST program.

The reflection coefficient of each station in the area was calculated using the method of Bhattacharya and Patra (1968), Olayinka (1996). Loke (1997) and Olasehinde and Bayewu (2011):

$K_{n}=\left(\rho_{n}-\rho_{n-1}\right) /\left(\rho_{n}+\rho_{n-1}\right)$,

where $K_{n}$ is reflection coefficient for the nth layer, $n$ is the number of layers, $\rho_{n}$ is the layer resistivity of the $n$th layer and $\rho_{n-1}$ is the layer resistivity overlying the $n$th layer.

\section{Results and discussion}

\section{Very low frequency-electromagnetic method (VLF- EM)}

Traverse 1 is $400 \mathrm{~m}$ in length (Fig. 3). The filtered real value ranges from -131.7 to 118.0 Siemens, while the filtered imaginary ranges from -30.3 to 68.9 Siemens. The 

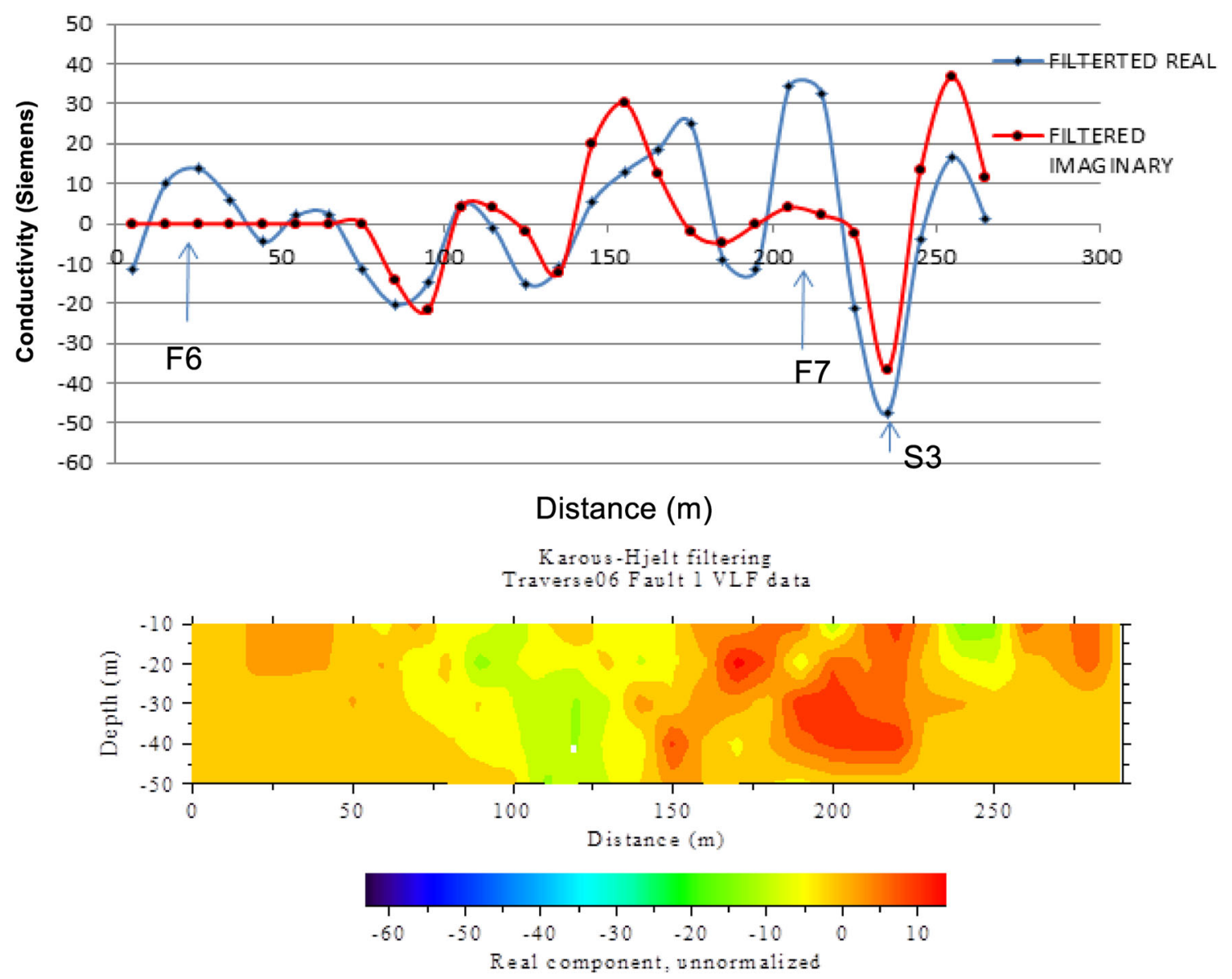

Fig. 8 The VLF-EM traverse and Karous-Hjelt pseudosection for Traverse 6

traverse shows the maximum peak at both positive and negative region with a more prominent filtered real peak at horizontal distance of 70-100 m. This usually signifies or corresponds to the area of high conductivity or area with the presence of fracture. This is marked F1 on the graph. The correspondent Karous-Hjelt pseudosection filtering confirms the moderately high conductivity which extends below $50 \mathrm{~m}$ depth. This conductivity could be due to the presence of fracture or accumulation of clayey materials. (McNeil and Labson 1992). Also at horizontal distance between 200 and $250 \mathrm{~m}$, there is an observation of the filtered real and filtered imaginary both positively peaking together; this usually signifies a relatively thick overburden (McNeil and Labson 1992). This area is, therefore, marked T1.

Traverse 2 (Fig. 4) is $700 \mathrm{~m}$ long (Fig. 4). The filtered real values ranges from -57.6 to 53.0 Siemens, while the filtered imaginary ranges from -52.0 to 51.5 Siemens. A fracture F2 is observed where the positive peak of the filtered real coincides with the negative peak of the imaginary at station 635 meters on the traverse. Also a thick overburden $\mathrm{T} 2$ is identified at distance between 310 and $350 \mathrm{~m}$ where the positive peak of filtered real and imaginary coincide. In the Karous-Hjelt filtering pseudo-section, the extent of the fractured identified is below $40 \mathrm{~m}$ depth, this can either be a localized zone of fracture or thick clayey materials in the region.

Traverse 3 is $600 \mathrm{~m}$ in length (Fig. 5). The filtered real values ranges from -28.7 to 69.2 Siemens, while the filtered imaginary ranges from -67.5 to 100.7 Siemens. A positive anomalous value of filtered real is observed at distance between 100 and $140 \mathrm{~m}$ and it is identified as a fracture F3. Area of thick overburden is observed at distance interval of 600 and $650 \mathrm{~m}$ and marked as T3. The Karous-Hjelt pseudosection also agrees with the plot and showed the extent of the identified fracture to be $40 \mathrm{~m}$ deep while the thick overburden is about $30 \mathrm{~m}$ deep.

Traverse 4(Fig. 6) is 400 metres in length. The filtered real values ranges from -305.4 to 142.2 Siemens, while the filtered imaginary values ranges from -17.8 to 20.7 Siemens. The profile shows a maximum peak at the positive region with a more prominent filtered real peak at 

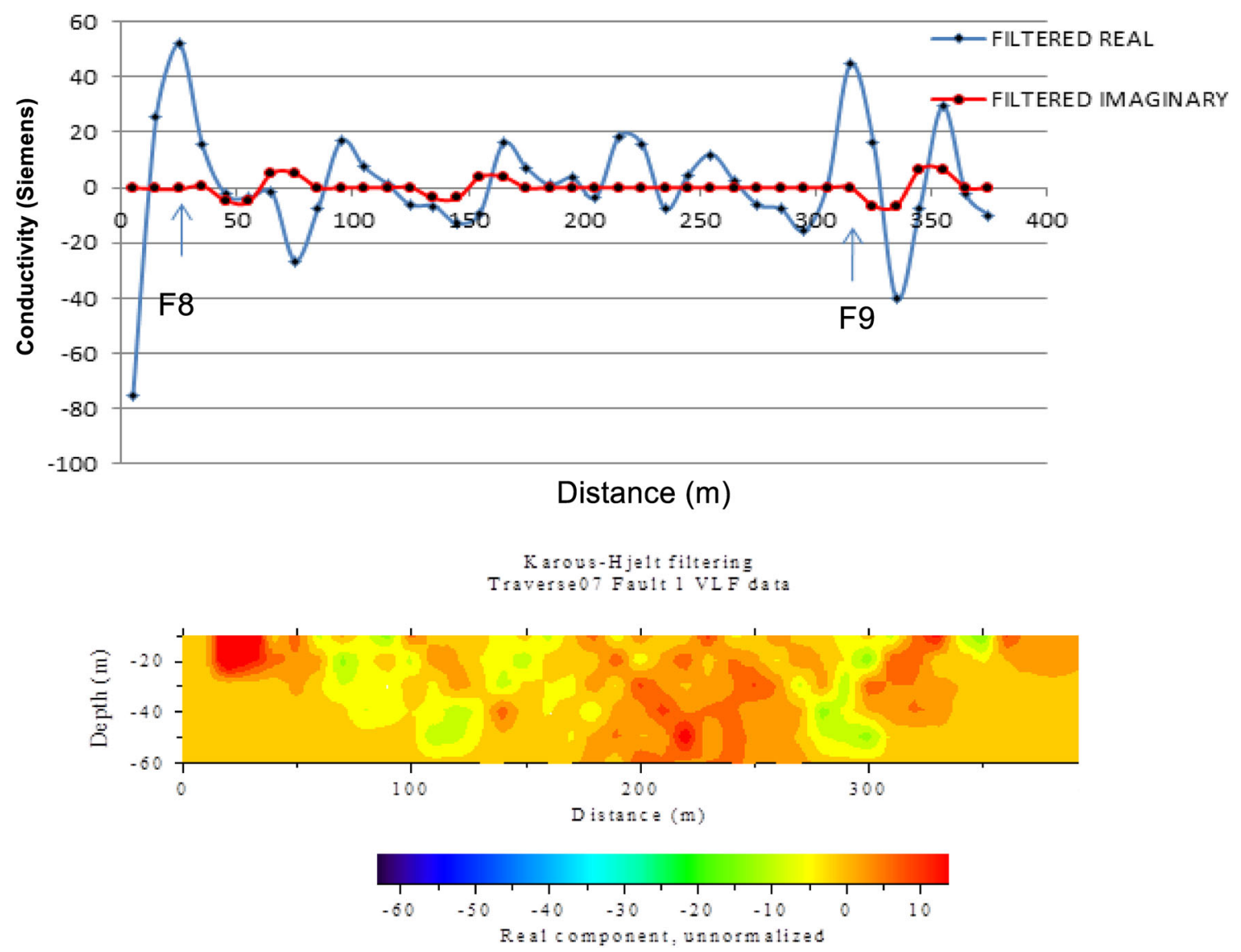

Fig. 9 The VLF-EM traverse and Karous-Hjelt pseudosection for Traverse 7

$285 \mathrm{~m}$, which also correspond to high conductive region. There are occurrences of fracture between at 270-290 m (F4a) and at 310-330 $\mathrm{m}$ (F4b) along this traverse. This also shows in the Karous-Hjelt filtering pseudo-section and reveal that the fractures extend to more than $50 \mathrm{~m}$.

Traverse 5 (Fig. 7) is also $400 \mathrm{~m}$ in length. The filtered real values ranges from -53.0 to 48.5 Siemens, while the filtered imaginary values ranges from -31.7 to 28.9 Siemens. The profile shows a maximum peak at positive region with a more prominent filtered real peak at $260 \mathrm{~m}$. The fracture, thick overburden, and shallow overburden are marked as F5, T4 and S2, respectively. The Karous-Hjelt pseudosection showed the extent of the identified fracture to be inclined and also extended to more than $50 \mathrm{~m}$ deep while the thick overburden is about $40 \mathrm{~m}$ deep.

Traverse 6 (Fig. 8) is 290 metres in length. The filtered real values range from -47.5 to 34.2 Siemens, while the filtered imaginary values ranges from -36.7 to $36.7 \mathrm{Sie}-$ mens. On the profile is S3 at point 230 metres with approximately width of $22 \mathrm{~m}$ and correspond to area of shallow overburden. Fractures F6 and F7 are observed on the traverse at 5-30 and 200-230 m, respectively. The Karous-Hjelt pseudosection showed that the extent of the identified fracture F6 extended to about $20 \mathrm{~m}$ deep while F7 extended to $45 \mathrm{~m}$ deep.

Traverse 7 (Fig. 9) is $400 \mathrm{~m}$. The filtered real value ranges from -73.5 to 552.1 Siemens, while the filtered imaginary ranges from -6.6 to 6.6 Siemens. The traverse shows a maximum peak of filtered real at $30 \mathrm{~m}$ along the traverse with width of about $40 \mathrm{~m}$; this is thus corresponded to fracture F8 and fracture F9 was observed at $320 \mathrm{~m}$ of the traverse with the width of about $30 \mathrm{~m}$. The Karous-Hjelt pseudosection showed the extent of the identified fracture F8 to be about $28 \mathrm{~m}$ deep while F9 is $40 \mathrm{~m}$ deep.

Traverse 8 (Fig. 10) is $400 \mathrm{~m}$ long. The filtered real values range from -203.7 to 146.8 Siemens, while the filtered imaginary ranges from 0.0 to 0.9 Siemens. The high maximum peak of the positive filtered real implies fractured zones, F10 was observed at $200 \mathrm{~m}$ of the traverse of 

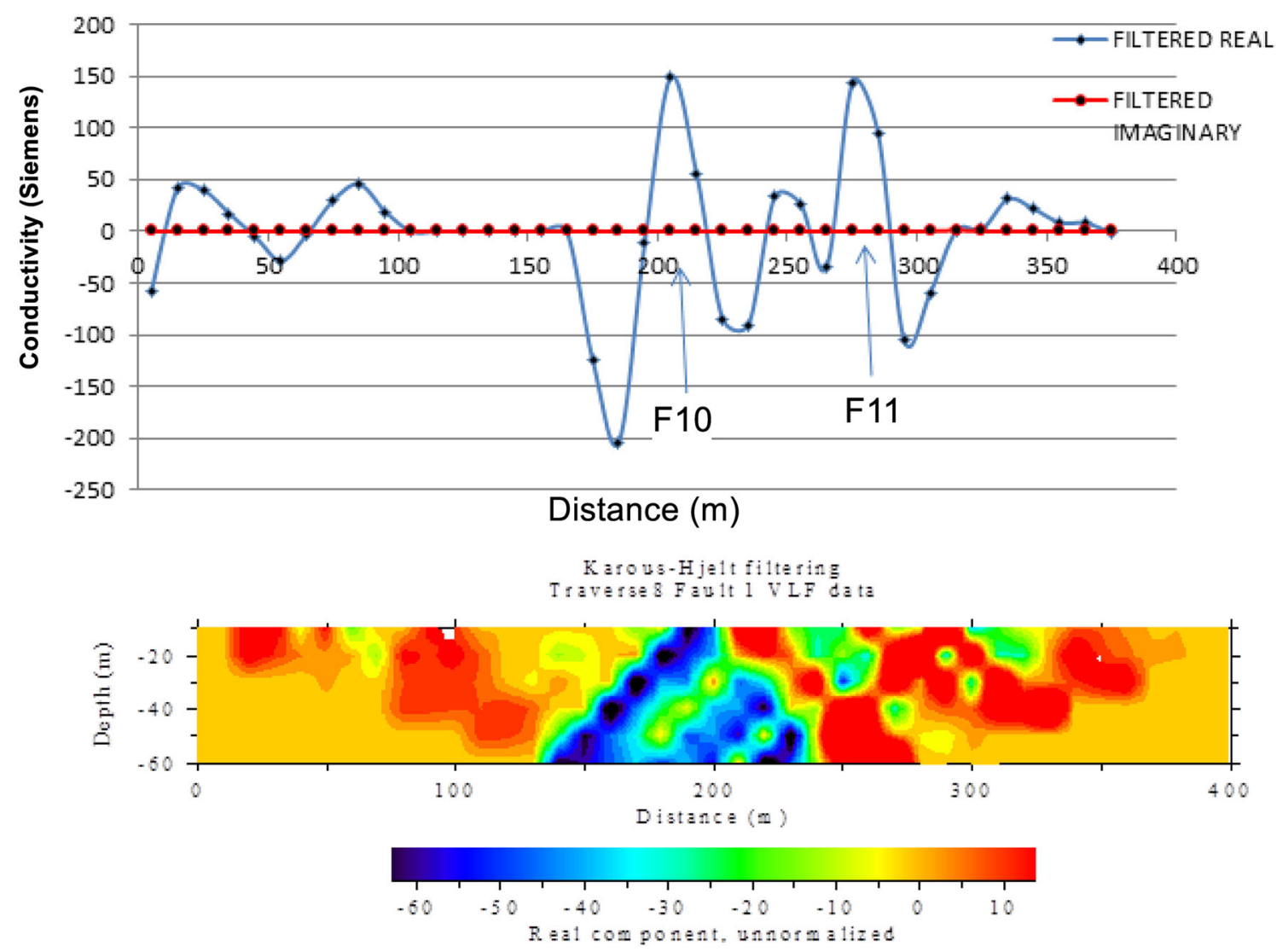

Fig. 10 The VLF-EM traverse and Karous-Hjelt pseudosection for Traverse 8

width of about $30 \mathrm{~m}$ and $\mathrm{F} 11$ at point $280 \mathrm{~m}$ with width of about $30 \mathrm{~m}$, respectively. The Karous-Hjelt pseudosection showed the identified fractures F10 and F11 to be inclined and they are also interconnected. They are extended to more than $40 \mathrm{~m}$ deep.

\section{Vertical electrical sounding (VES) data}

The areas delineated as high conductive/fracture zones and thick overburden along the traverse were considered as points of interest in the VES survey.

Interpretation of VES data is both quantitative and qualitative, it involves the determination of the thickness and resistivity of different horizons and the inference of their lithologies based on their resistivity and reflection coefficient values.

The curve types observed in the area are 3-layer H-type (26\%); 4-layer HA-type (9\%) and $\mathrm{KH}(52 \%)$; and 5-layer HKH-type (13\%). The curve types include KH, HA, HKH and $\mathrm{H}$. The $\mathrm{KH}$ type is the most predominant and it is typical of tropics area (Olayinka and Olorunfemi 1992). It is often possible to make qualitative hydrologic deduction from curve type (Worthington 1993).
Typical iterated curves generated from the field measurements in the area are shown in Fig. 11. Table 1 revealed the geoelectric parameters of the various layers and showed the inferred lithologies from the geoelectric interpretation.

The geoelectric interpretation revealed 3-5 geoelectric layers: top soil $(66-870 \Omega \mathrm{m})$, the weathered layer which comprises of clay/clayey sand/sand/laterite (28.3-2342.7 $\Omega \mathrm{m}$ ), underlying this layer is the fractured basement $(480.0-1415.9 \Omega \mathrm{m})$ and the fresh basement (655.9-18,265.4 $\Omega \mathrm{m})$. The fractured and fresh basement layers were differentiated using the values of reflection coefficient obtained from each VES point, which is the measure of competence of the basement layer. (Olayinka 1996; Olasehinde and Bayewu 2011). From the calculated reflection coefficient, the reflection coefficient map was produced (Fig. 12) and shows a value range of (0.59-0.98). Olayinka (1996) observed that an area of lower reflection coefficient value $(<0.8)$ exhibits weathered or fractured basement rock thus, favors a high water potential. Therefore, areas with relatively lower reflection coefficient (i.e. $<0.8)$ represents areas where the bedrock is fractured/ or intensely weathered. 


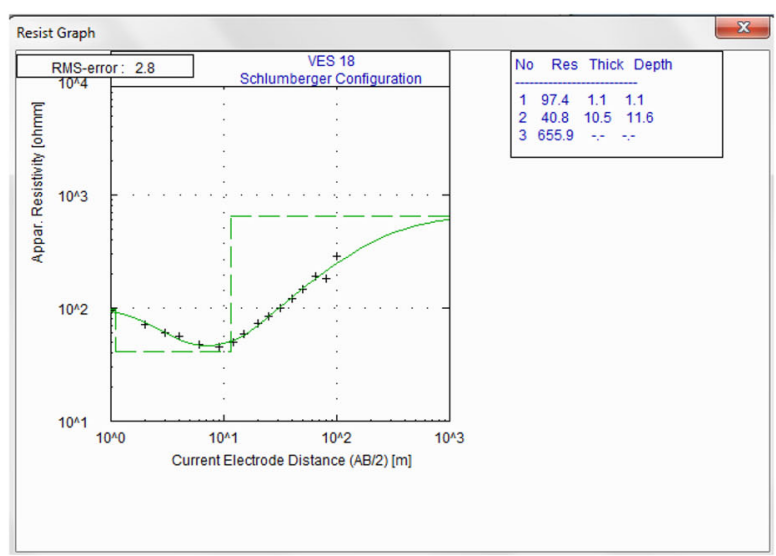

(a) Three layer $\mathrm{H}$ type curve

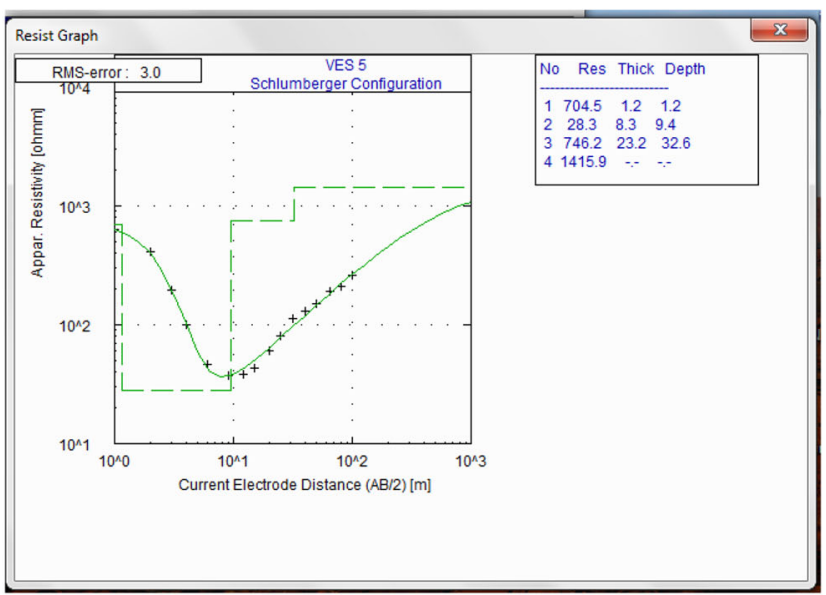

(c) Four layer KH type curve

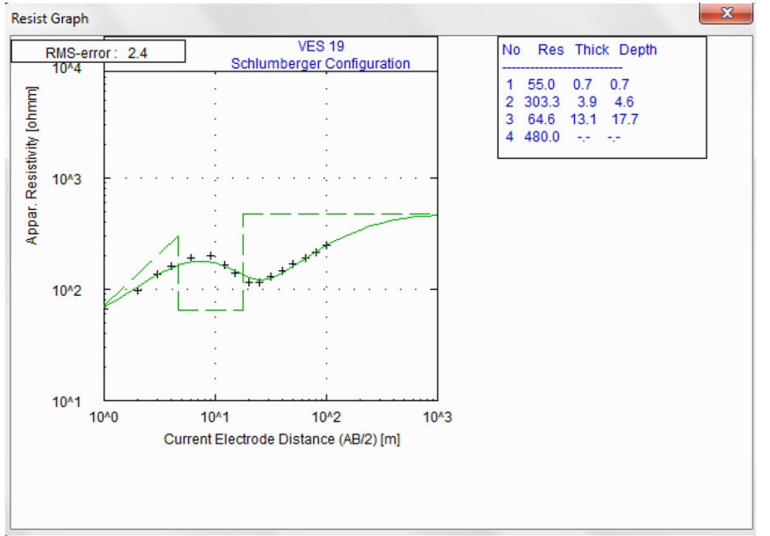

(b) Four layer HA type curve

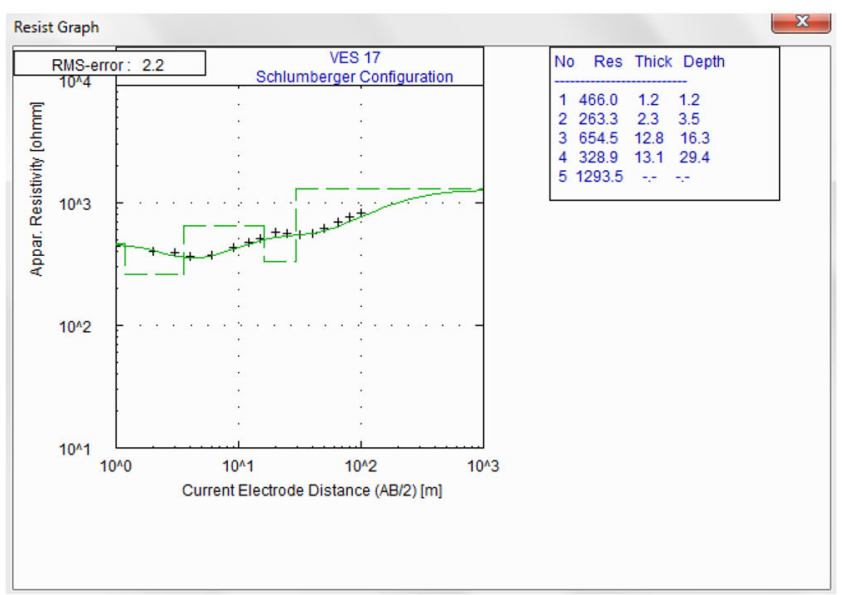

(d) Five layer HKH type curve

Fig. 11 Typical VES curve types observed in the study area (a-d)

Table 1 Results of vertical electrical sounding

\begin{tabular}{|c|c|c|c|c|c|c|}
\hline No. of VES & No. of layers & Resistivity & Thickness & Depth & Reflection coefficient & Description \\
\hline \multirow[t]{4}{*}{1} & 1 & 192.8 & 0.7 & 0.7 & \multirow[t]{4}{*}{0.98} & Sandy top soil \\
\hline & 2 & 421.5 & 1.1 & 1.9 & & Sandy layer \\
\hline & 3 & 57.2 & 6.0 & 7.9 & & Clayey layer \\
\hline & 4 & 5691.9 & Infinite & Infinite & & Fresh basement \\
\hline \multirow[t]{3}{*}{2} & 1 & 285.0 & 1.4 & 1.4 & \multirow[t]{3}{*}{0.94} & Sandy top soil \\
\hline & 2 & 30.2 & 8.0 & 9.3 & & Clay layer \\
\hline & 3 & 1005.1 & Infinite & Infinite & & Fresh basement \\
\hline \multirow[t]{4}{*}{3} & 1 & 326.9 & 1.1 & 1.1 & \multirow[t]{4}{*}{0.59} & Top soil \\
\hline & 2 & 768.1 & 3.5 & 4.6 & & Sandy layer/laterite \\
\hline & 3 & 420.4 & 1.7 & 6.3 & & Weathered basement \\
\hline & 4 & 580.2 & Infinite & Infinite & & Fractured basement \\
\hline \multirow[t]{4}{*}{4} & 1 & 334.5 & 0.9 & 0.9 & \multirow[t]{4}{*}{0.92} & Top soil \\
\hline & 2 & 392.8 & 1.3 & 2.2 & & Sandy layer \\
\hline & 3 & 73.7 & 4.2 & 6.4 & & Clay layer \\
\hline & 4 & 1018.9 & Infinite & Infinite & & Fresh basement \\
\hline \multirow[t]{2}{*}{5} & 1 & 704.5 & 1.2 & 1.2 & \multirow[t]{2}{*}{0.31} & Top soil \\
\hline & 2 & 28.3 & 8.3 & 9.4 & & Clay layer \\
\hline
\end{tabular}


Table 1 continued

\begin{tabular}{|c|c|c|c|c|c|c|}
\hline No. of VES & No. of layers & Resistivity & Thickness & Depth & Reflection coefficient & Description \\
\hline & 3 & 746.2 & 23.2 & 32.6 & & Fractured basement \\
\hline & 4 & 1415.9 & Infinite & Infinite & & Fresh basement \\
\hline \multirow[t]{3}{*}{6} & 1 & 126.4 & 0.4 & 0.4 & 0.87 & Top soil \\
\hline & 2 & 44.8 & 6.3 & 6.8 & & Clay layer \\
\hline & 3 & 665.5 & Infinite & Infinite & & Fresh basement \\
\hline \multirow[t]{4}{*}{7} & 1 & 98.2 & 0.7 & 0.7 & 0.89 & Top soil \\
\hline & 2 & 44.4 & 1.5 & 2.2 & & Clay layer \\
\hline & 3 & 458.8 & 39.8 & 42.0 & & Fractured basement \\
\hline & 4 & 7956.5 & Infinite & Infinite & & Fresh basement \\
\hline \multirow[t]{4}{*}{8} & 1 & 157.4 & 0.9 & 0.9 & 0.95 & Top soil \\
\hline & 2 & 305.4 & 2.6 & 3.5 & & Sandy layer \\
\hline & 3 & 64.9 & 20.7 & 24.2 & & Clay layer \\
\hline & 4 & 2449.2 & Infinite & Infinite & & Fresh basement \\
\hline \multirow[t]{4}{*}{9} & 1 & 92.5 & 0.9 & 0.9 & 0.96 & Top soil \\
\hline & 2 & 153.3 & 6.6 & 7.5 & & Sandy layer \\
\hline & 3 & 88.0 & 18.2 & 25.7 & & Clayey layer \\
\hline & 4 & 4711.2 & Infinite & Infinite & & Fresh basement \\
\hline \multirow[t]{3}{*}{10} & 1 & 217.4 & 0.5 & 0.5 & 0.92 & Top soil \\
\hline & 2 & 49.1 & 10.8 & 11.4 & & Clayey layer \\
\hline & 3 & 1173.5 & Infinite & Infinite & & Fresh basement \\
\hline \multirow[t]{4}{*}{11} & 1 & 66.1 & 1.8 & 1.8 & 0.91 & Top soil \\
\hline & 2 & 288.6 & 7.0 & 13.9 & & Sandy layer \\
\hline & 3 & 99.7 & 21.4 & 30.4 & & Weathered basement \\
\hline & 4 & 2035.1 & Infinite & Infinite & & Fresh basement \\
\hline \multirow[t]{4}{*}{12} & 1 & 144.5 & 1.9 & 1.9 & 0.64 & Top soil \\
\hline & 2 & 396.4 & 22.6 & 22.5 & & Sandy layer \\
\hline & 3 & 140.6 & 41.1 & 65.6 & & Clayey sand \\
\hline & 4 & 708.6 & Infinite & Infinite & & Fractured basement \\
\hline \multirow[t]{4}{*}{13} & 1 & 733.4 & 0.9 & 0.9 & 0.98 & Top soil \\
\hline & 2 & 1012.7 & 3.1 & 3.9 & & Lateritic rock \\
\hline & 3 & 77.0 & 11.5 & 15.4 & & Clayey layer \\
\hline & 4 & 9302.6 & Infinite & Infinite & & Fresh basement \\
\hline \multirow[t]{4}{*}{14} & 1 & 133.7 & 1.0 & 1.0 & 0.98 & Sandy top soil \\
\hline & 2 & 161.9 & 2.6 & 3.6 & & Sandy layer \\
\hline & 3 & 35.4 & 8.7 & 12.3 & & Clayey layer \\
\hline & 4 & 4783.0 & Infinite & Infinite & & Fresh basement \\
\hline \multirow[t]{4}{*}{15} & 1 & 82.1 & 0.7 & 0.7 & 0.96 & Clayey sand \\
\hline & 2 & 288.5 & 1.6 & 2.3 & & Sandy layer \\
\hline & 3 & 52.7 & 8.6 & 10.9 & & Clayey layer \\
\hline & 4 & 3181.0 & Infinite & Infinite & & Fresh basement \\
\hline \multirow[t]{5}{*}{16} & 1 & 183.4 & 1.0 & 1.0 & 0.94 & Top soil \\
\hline & 2 & 141.3 & 5.7 & 6.7 & & Clayey sands \\
\hline & 3 & 306.9 & 9.4 & 16.0 & & Sandy layer \\
\hline & 4 & 202.1 & 16.8 & 32.8 & & Weathered or fractured rock \\
\hline & 5 & 6560.2 & Infinite & Infinite & & Fractured basement \\
\hline \multirow[t]{3}{*}{17} & 1 & 466.0 & 1.2 & 1.2 & 0.59 & Sandy top soil \\
\hline & 2 & 263.3 & 2.3 & 3.5 & & Clayey sand \\
\hline & 3 & 654.5 & 12.8 & 16.3 & & Sandy layer \\
\hline
\end{tabular}


Table 1 continued

\begin{tabular}{|c|c|c|c|c|c|c|}
\hline No. of VES & No. of layers & Resistivity & Thickness & Depth & Reflection coefficient & Description \\
\hline & 4 & 328.9 & 13.1 & 29.4 & & Weathered basement \\
\hline & 5 & 1293.5 & Infinite & Infinite & & Fractured basement \\
\hline \multirow[t]{3}{*}{18} & 1 & 97.4 & 1.1 & 1.1 & 0.88 & Top soil \\
\hline & 2 & 40.8 & 10.5 & 11.6 & & Clayey layer \\
\hline & 3 & 655.9 & Infinite & Infinite & & Fresh basement \\
\hline \multirow[t]{4}{*}{19} & 1 & 55.0 & 0.7 & 0.7 & 0.76 & Top soil \\
\hline & 2 & 303.3 & 3.9 & 4.6 & & Sandy layer \\
\hline & 3 & 64.6 & 13.1 & 17.7 & & Clayey layer \\
\hline & 4 & 480.0 & Infinite & Infinite & & Fractured basement \\
\hline \multirow[t]{4}{*}{20} & 1 & 277.1 & 0.6 & 0.6 & 0.96 & Top soil \\
\hline & 2 & 1833.3 & 1.8 & 2.4 & & Sandy layer \\
\hline & 3 & 115.2 & 10.5 & 12.9 & & Weathered rock \\
\hline & 4 & 6694.7 & Infinite & Infinite & & Fresh basement \\
\hline \multirow[t]{3}{*}{21} & 1 & 174.6 & 1.6 & 1.6 & 0.99 & Top soil \\
\hline & 2 & 28.8 & 5.0 & 6.7 & & Clayey layer \\
\hline & 3 & 6166.4 & Infinite & Infinite & & Fresh basement \\
\hline \multirow[t]{4}{*}{22} & 1 & 870.2 & 0.6 & 0.6 & 0.98 & Sandy top soil \\
\hline & 2 & 345.5 & 1.4 & 2.0 & & Sandy layer \\
\hline & 3 & 2342.7 & 4.7 & 6.8 & & Lateritic layer \\
\hline & 4 & $18,265.4$ & Infinite & Infinite & & Fresh basement \\
\hline \multirow[t]{3}{*}{23} & 1 & 475.0 & 1.5 & 1.5 & 0.92 & Sandy top soil \\
\hline & 2 & 94.1 & 7.7 & 9.3 & & Sandy clay \\
\hline & 3 & 2208.1 & Infinite & Infinite & & Fresh basement \\
\hline
\end{tabular}

Fig. 12 Map of the reflection coefficient in the study area

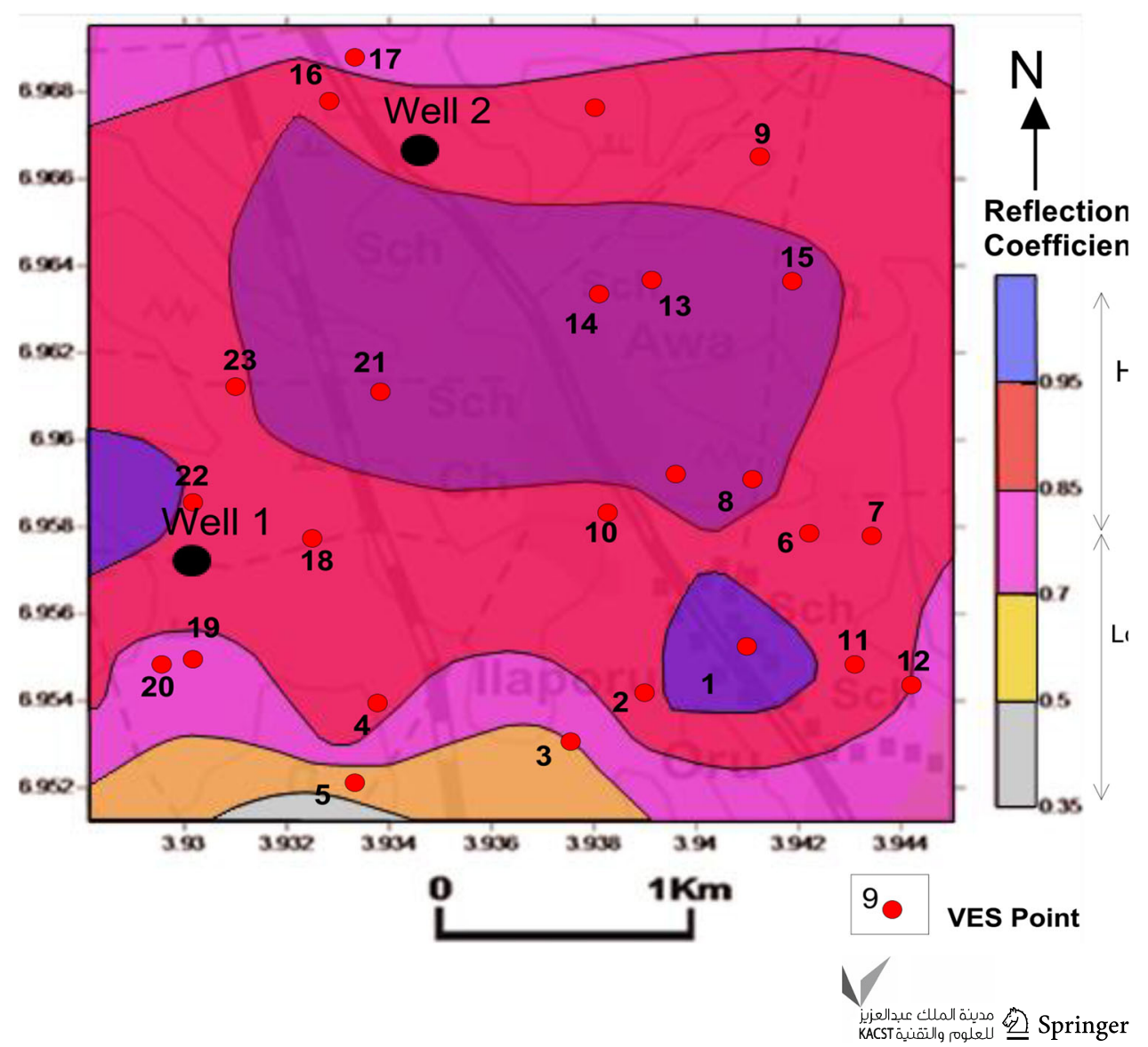


Fig. 13 The Iso-resistivity map of the study area

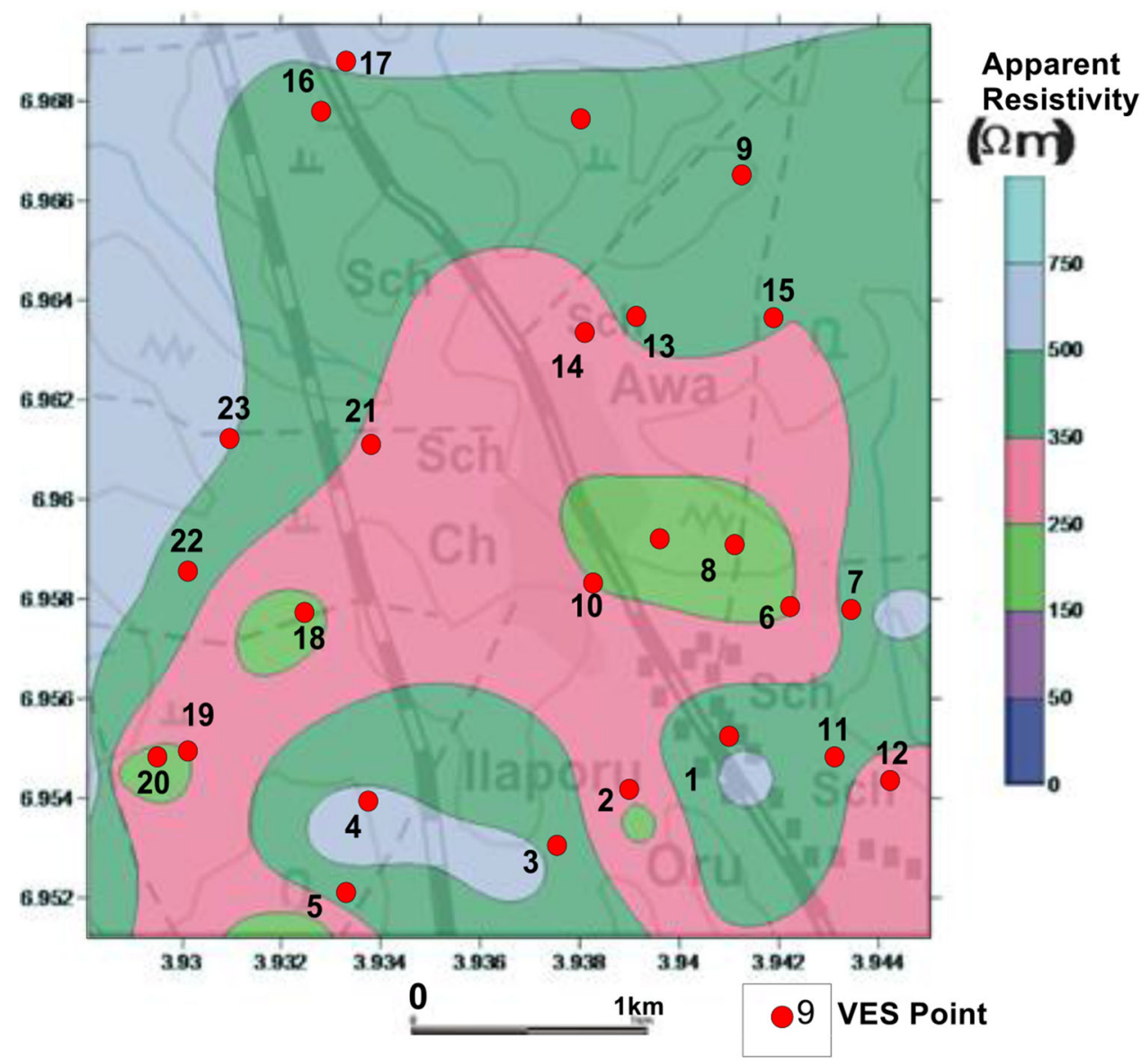

The apparent resistivity values of the area were contoured to produce the isoresistivity map (Fig. 13) and it revealed that the apparent resistivity increases radially from the central part of area outwardly. The resistivity ranges between $150-850 \Omega \mathrm{m}$.

The overburden thickness in the area varies between 6.3 and $65.6 \mathrm{~m}$. The isopach map of the area (Fig. 14) showed overburden thickness range of $20-50 \mathrm{~m}$ at the northern, eastern and some part at the south of the study area, while the relatively thin overburden thickness of about 5-15 m were noticed virtually around the central and western part study area. The overburden thickness is shallow in most part of the probing stations, which indicates the closeness of the basement to the surface. Therefore, groundwater occurrence in this area will largely depend on the occurrence of fractures in areas where there is thin overburden thickness. From the VES interpreted result, it can be deduced that VES 5, VES 7, VES 8, VES 9, VES 11, VES 12, VES 16, VES 17 and VES 19 are the most promising areas for the sitting of boreholes based on consideration of resistivities of the last layer, overburden thickness, or its respective reflection coefficient according to Olayinka (1996).

\section{Groundwater potential evaluation}

The groundwater potential of a basement complex area is determined by a complex inter-relationship between the geology, post emplacement tectonic history, weathering processes and depth, nature of the weathered layer, groundwater flow pattern, recharge and discharge processes (Olorunfemi et al. 2004). Decrease in the reflection coefficient and relatively high overburden thickness 
Fig. 14 Isopach map of the overburden in the study area

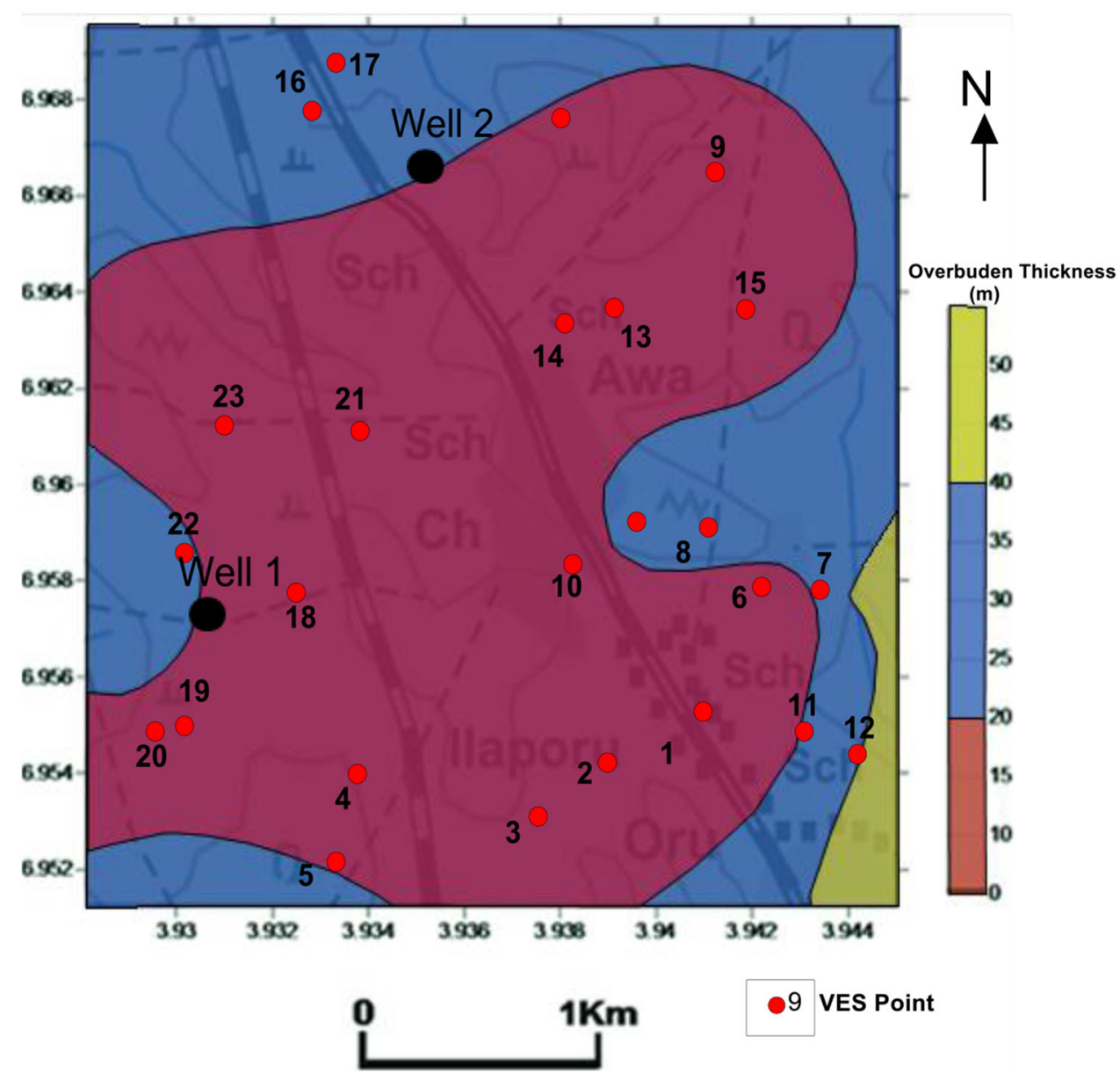

enhance the productivity of boreholes in some parts of the basement complex of southwestern Nigeria (Olorunfemi and Olorunniwo 1985).

The present evaluation of the groundwater potential of the study area has been based on aquifer geoelectrical parameters obtained from VES interpretation result. Some of the factors that are considered for groundwater potential in the study area are, overburden thickness, reflection coefficient and presence of fractures and these are expressed in Table 2.

Based on the aforementioned factors, groundwater potential map of the study area was produced from the data in Table 2, and the potential of groundwater in the study area is delineated into three (3) segments: the high groundwater potential, the medium groundwater potential and the low groundwater potential. Three basic criteria were considered in evaluating promising points for groundwater potential: i. Areas with high yield: These are the areas with overburden thickness greater than $13 \mathrm{~m}$ and/or with reflection coefficient less than 0.8.

ii. Areas with medium yield: (i) Areas with overburden thickness greater than $13 \mathrm{~m}$ but less than $30 \mathrm{~m}$ and with reflection coefficient greater than or equal to 0.8

iii. Areas potential with low yield are: (i) Areas with overburden thickness less than $13 \mathrm{~m}$ and or with reflection coefficient greater than or equal to 0.8 .

Based on these criteria, the northern, northeastern and eastern areas have the highest and brightest potential for future groundwater exploration and development in addition to the existing ones in the study area, while the medium and the low yield water potential are found at the western and central part of the area.

Apart from the hand dug wells in this area, two prominent water boreholes are present and were dug by 
Table 2 Groundwater Potential across the 23 VES stations

\begin{tabular}{|c|c|c|c|c|}
\hline VES Station & Overburden thickness (m) & Reflection coefficient & Presence of fracture/weathered rock & Remark \\
\hline 1 & 7.8 & 0.98 & - & Low yield \\
\hline 2 & 9.4 & 0.94 & - & Low yield \\
\hline 3 & 6.3 & 0.59 & Fracture available & Medium yield \\
\hline 4 & 6.4 & 0.92 & - & Low yield \\
\hline 5 & 32.7 & 0.62 & Fracture available & High yield \\
\hline 6 & 6.7 & 0.87 & Weathered rock & High yield \\
\hline 7 & 42.0 & 0.89 & Weathered rock & High yield \\
\hline 8 & 24.2 & 0.95 & - & High yield \\
\hline 9 & 25.7 & 0.96 & - & Medium yield \\
\hline 10 & 11.3 & 0.92 & Weathered rock & Medium yield \\
\hline 11 & 30.2 & 0.91 & Weathered rock & High yield \\
\hline 12 & 65.6 & 0.64 & Fracture available & High yield \\
\hline 13 & 23.6 & 0.98 & - & Medium yield \\
\hline 14 & 12.3 & 0.98 & Weathered rock & Medium yield \\
\hline 15 & 10.9 & 0.96 & Weathered rock & Medium yield \\
\hline 16 & 33.0 & 0.94 & Weathered rock & High yield \\
\hline 17 & 29.4 & 0.59 & Fracture available & High yield \\
\hline 18 & 11.6 & 0.88 & Weathered rock & Medium yield \\
\hline 19 & 17.7 & 0.76 & Partially Fractured & High yield \\
\hline 20 & 12.9 & 0.96 & Weathered rock & High yield \\
\hline 21 & 6.6 & 0.99 & - & Low yield \\
\hline 22 & 6.7 & 0.98 & - & Low yield \\
\hline 23 & 9.2 & 0.92 & - & Low yield \\
\hline
\end{tabular}

individuals to get a more hygienic and good quality water to drink. These wells are located in the part of the study area shown in Fig. 15. Well 1 has a low yield. Most times, it is usually pumped twice in a day (Early morning and evening) into a storage tank and the quantity of water per community member is strictly controlled as a result of the low yield. Well 2, however, is located in area classified as having high groundwater potential. Unlike Well 1, Well 2 yield is higher and quantity of water per community member is not controlled and the well is left for the community to fetch continuously unregulated. The existing wells confirm the reliability of the groundwater potential map, hence the map provides a useful guide for further groundwater development.

\section{Conclusion}

The combination of electromagnetic profiling and vertical electrical resistivity surveys in the study area has contributed to a better understanding of the groundwater occurrence in this part of basement complex of Southwestern Nigeria. Geological features suspected to be basement fractures (zones of high conductivities) identified from VLF-EM anomaly curves were confirmed by geoelectric subsurface information developed from interpretation results of vertical electrical soundings. Three (3) to five (5) major subsurface geoelectric layers were delineated from VES interpretation result; these include the top soil (mostly sandy), sandy or lateritic layer clay or sandy clay (partly weathered to weathered layer) and the basement bedrock (fractured/fresh basement). Other VES stations have appreciable groundwater within the weathered layer but because of high reflection coefficient $(>0.8)$ which indicates that the basement beneath is fresh, it might not harbor or store adequate or sufficient groundwater, the borehole, when drilled might not be productive enough. Integration of VLF-EM and electrical resistivity sounding results enabled identification of good site for productive borehole and groundwater in a typical crystalline terrain as the studied area. The Groundwater potential map produced shows a reliable agreement with the groundwater discharge from existing boreholes within the study area.

It is, however, recommended that detailed studies which might involve the use of multiple approach such as statistical modeling coupled with remote sensing data should be used to predict the groundwater potential of the covered areas more accurately and faster. This will also help to 


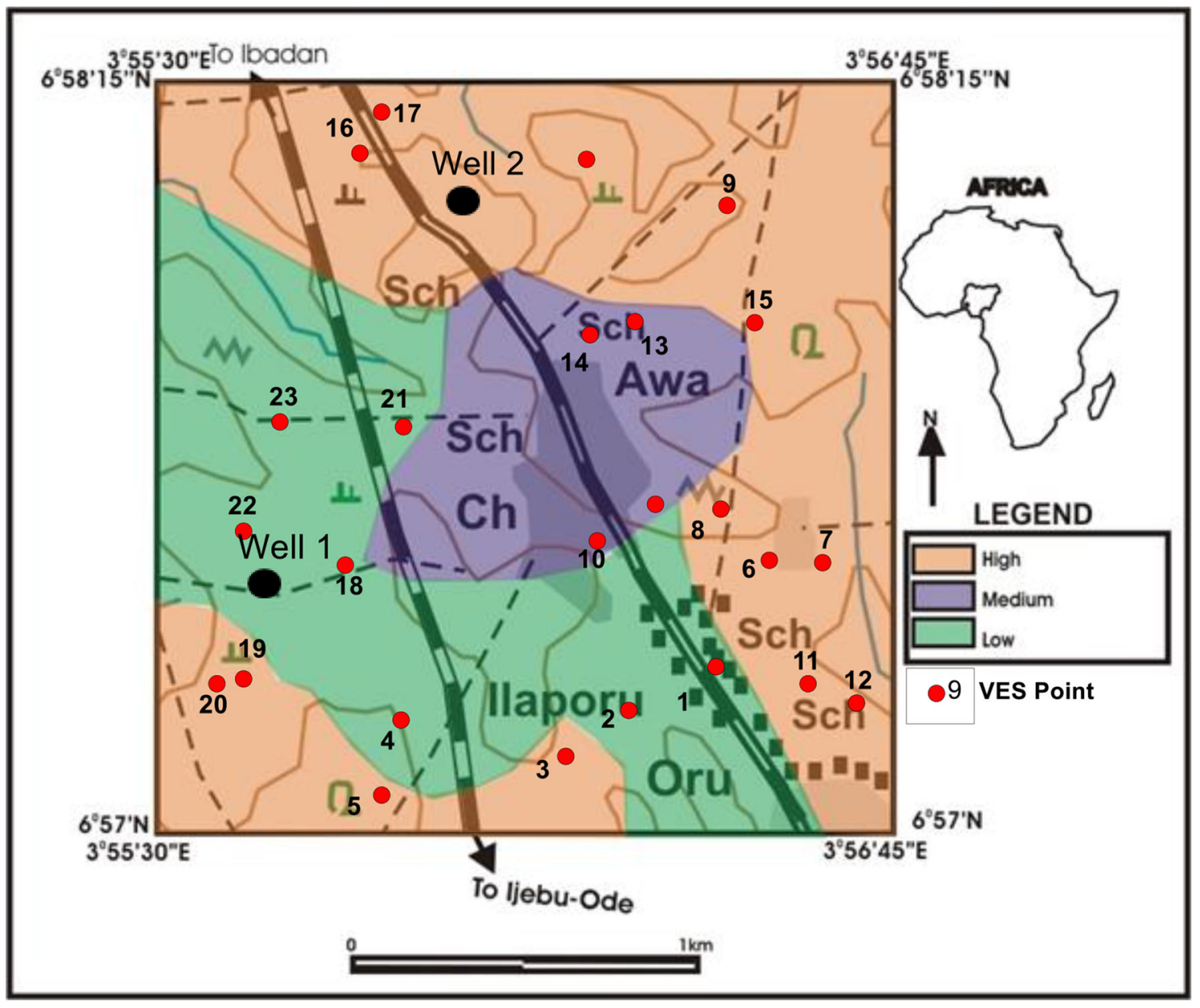

Fig. 15 Groundwater potential map of the study area

cover wider area extent and, therefore, help the communities locally and on regional basis.

Open Access This article is distributed under the terms of the Creative Commons Attribution 4.0 International License (http:// creativecommons.org/licenses/by/4.0/), which permits unrestricted use, distribution, and reproduction in any medium, provided you give appropriate credit to the original author(s) and the source, provide a link to the Creative Commons license, and indicate if changes were made.

\section{References}

Anbazhagan S, Balamurugan G, Biswal TK (2011) Remote sensing in delineating deep fracture aquifer zones. In: Anbazhagan S, Subramanian SK, Yang X (eds) Geoinformatics in APPLIED GEOMORPHOLOGY. CRC Press, Taylor and Francis, pp 205-229

Ariyo SO, Oduwole MG, Mosuro GO (2003) Hydro-geophysical evaluation of groundwater potentials of Awa-Ijebu, southwestern Nigeria. J Niger Assoc Hydrogeol 14:13-21

Balamurugan G, AnbazhaganS, Biswal TK (2008) Remote sensing for delineating deep aquifer zones, Hosur-Rayakottai region, India. In: 2008 (Ed.), National Symposium on Advances in remote sensing technology and applications with Specia 1Emphasis on microwave remote sensing and annual convention of Indian Society of Remote Sensing (ISRS). Ahmedabad, Gujarat, India

Bhattacharya PK, Patra HP (1968) Direct current geoelectric sounding methods in geochemistry and geophysics. Elsevier, Amsterdam, p 135

Davoodi MD, Rezaei M, Pourghasemi HR, Pourtaghi ZS, Pradhan B (2013) Groundwater spring potential mapping using bivariate statistical model and GIS in the Taleghan watershed Iran. Arab J Geosci. doi:10.1007/s12517-013-1161-5

Evans BM, Myers WL (1990) A GIS-based approach to evaluating regional groundwater pollution potential with DRASTIC. J Soil Water Conserv 45(2):242-245

Fraser DC (1969) Contouring of VLF-EM data. Geophysics 34(6):958-967

Iloeje LP (1986) A new geography of Nigeria New Revised Edition. Longman Group, London, p 115

Kellgren N (2002) Applicability of remote sensing techniques to groundwater exploration in semi-arid hard rock terrain-a systematic approach. PhD thesis, Chalmers Publication Library-Chalmers University of Technology, Götebor

Kumar T, Gautam AK, Kumar T (2014) Appraising the accuracy of GIS-based Multi-criteria decision making technique for delineation of Groundwater potential zones. Water Resour Manag 28:4449-4466. doi:10.1007/s11269-014-0663-6 
Loke MH (1997) Electrical Imaging surveys for Environmental and Engineering Studies. A partial guide to 2-D and 3-D surveys. Minden Heights, 11700, Penang, Malaysia

McNeil JD, Labson VF (1992) Geological mapping using VLF radio fields. In: Nabighian M (ed) Electromagnetic methods in applied geophysics, vol 2. Society of Exploration Geophysicists, Tulsa, pp $10-12$

Murthy KSR, Mamo AG (2009) Multi-criteria decision evaluation in groundwater zones identification in Moyale-Teltele subbasin, South Ethiopia. Int J Remote Sens 30:2729-2740

Naghibi A, Pourghasemi HR (2015) A comparative assessment between three machine learning models and their performance comparison by bivariate and multivariate statistical methods for groundwater potential mapping in Iran. Water Resour Manag 29(14):5217-5236. doi:10.1007/s11269-015-1114-8

Naghibi SA, Pourghasemi HR, Dixon B (2016) Groundwater spring potential using boosted regression tree, classification and regression tree, and random forest machine learning models in Iran. Environ Monit Assess 188:44. doi:10.1007/s10661-0155049-6

Offodile ME (1983) The occurrence of exploitation groundwater in Nigeria Basement rocks. Nig J Min Geol 20:131-146

Ogunrayi AO, Akinseye FM, Goldberg V, Bernhofer C (2016) Descriptive analysis of rainfall and temperature trends over Akure, Nigeria. J Geogr Reg Plann 9(11):195-202

Okwueze EE (1996) Preliminary findings of the groundwater resource potentials from a regional geo-electric survey of the Obudu basement area. Nig Global J Pure Appl Sci 2(2):201-211

Oladapo MI, Akintorinwa OJ (2007) Hydrogeophysical study of Ogbese, southwestern Nigeria. Glob J Pure Appl Sci 13(1):55-61

Olasehinde PI, Bayewu OO (2011) Evalution of Electrical resistivity anisotropy in geological mapping: a case study of Odo Ara, west central Nigeria. Afr J Environ Sci Technol 5(7):553-556

Olayinka AI (1996) Non uniqueness in the interpretation of bedrock resistivity from sounding curve and its hydrological implications. Water Resour J NAH 7(1\&2):55-60

Olayinka AI, Olorunfemi MO (1992) Determination of geoelectrical characteristics in Okene area and implication for borehole setting. J Min Geol 28:403-412

Olorunfemi MO, Fasuyi SA (1993) Aquifer types and the geoelectric/ hydrologic characteristics of part of the central basement terrain of Nigeria (Niger State). J Afr Earth Sci 16:309-317

Olorunfemi MO, Olorunniwo MA (1985) Geoelectric parameter and aquifer characteristics of some parts of southwestern Nigeria. Geol Appl E Hydrogeol Part 2:99-109

Olorunfemi MO, Afolayan JF, Afolabi O (2004) Geoelectric/electromagnetic VLF survey for groundwater in a Basement Terrain: a case Study. Ife J Sci 6(1):74-78

Oloruntola M, Adeyemi GO (2014) Geophysical and hydrochemical evaluation of groundwater potential and character of Abeokuta area, southwestern Nigeria. J Geogr Geol 6(3):162-177

Omosuyi GO, Ojo JS, Enikanselu PA (2003) Geophysical investigation for groundwater of Obanla-Obakekere in Akure Area within the Basement Complex of South Western Nigeria. J Min Geol 3(2):109-116
Onakomaiya SO, Oyesiku OO, Jegede FI (eds) (1992) Ogun State in maps. Rex Charles Publication, Ibadan, p 187

Ozdemir A (2011) GIS-based groundwater spring potential mapping in the Sultan Mountains (Konya, Turkey) using frequency ratio, weights of evidence and logistic regression methods and their comparison. J Hydrol 411(3-4):290-308

Parasnis DS (1986) Principles of applied geophysics. Chapmans and Hall, London

Pourghasemi HR, Beheshtirad M (2015) Assessment of a data driven evidential belief function model and GIS for groundwater potential mapping in the Koohrang watershed, Iran. Geocarto Int 30(6):662-685. doi:10.1080/10106049.2014.966161

Pourtaghi ZS, Pourghasemi HR (2014) GIS-based groundwater spring potential assessment and mapping in the Birj and Township, southern Khorasan Province, Iran. Hydrogeology 22:643-662. doi:10.1007/s10040-013-1089-6

Pradhan B (2009) Groundwater potential zonation for basaltic watersheds using satellite remote sensing data and GIS techniques. Cent Eur J Geosci 1(1):120-129

Rahmati O, Pourghasemi HR, Melesse A (2016) Application of GISbased data driven random forest and maximum entropy models for groundwater potential mapping: a case study at Mehran Region, Iran. Catena 137:360-372. doi:10.1016/j.catena.2015. 10.010

Sener E, Davraz A, Ozcelik M (2005) An integration of GIS and remote sensing in groundwater investigations: a case study in Burdur, Turkey. Hydrogeol J 13(5-6):826-834

Sharma MP, Kujur A (2012) Application of Remote Sensing and GIS for groundwater recharge zone in and around Gola Block, Ramgargh district, Jharkhand, India. Int J Sci Res Publ 2(2):1-6

Singh PK, Singh UC (2009) Water resource evaluation and management for Morar River Basin, Gwalior district, Madhya Pradesh, using GIS e-journal. Earth Sci India 2(III):174-186

Solomon S, Quiel F (2006) Groundwater study using remote sensing and geographic information systems (GIS) in the central highlandsof Eritrea. Hydrogeol J 14(5):1029-1041

Telford WM, Geldart LP, Sheriff RE, Keys DA (1976) Applied geophysics. Cambridge University Press, Cambridge, p 282

White IF (1986) An assessment of geophysical method applied to basement aquifer studies in Masvingo Province, Zimbabwe. Commonwealth Science Council Technical Paper 273, vol 11, pp 14-32

Worthington PF (1993) The Uses and abuses of archie equations: the formation factor-porosity relationship. J Appl Geophys 30:215-228

Zabihi M, Pourghasemi HR, Pourtaghi ZS, Behzadfar M (2016) GISbased multivariate adaptive regression spline and random forest models for groundwater potential mapping in Iran. Environ Earth Sci 75:665. doi:10.1007/s12665-016-5424-9

\section{Publisher's Note}

Springer Nature remains neutral with regard to jurisdictional claims in published maps and institutional affiliation. 